\title{
Supervivencia de la medicina primitiva y empírica
} Parte 2

\section{Survival of primitive medicine and empirical Part. 2}

\section{Supervivência da medicina primitiva e empírica Parte 2}

doi) http://dx.doi.org/10.35954/SM2020.39.1.9

Dr. Augusto Soiza Larrosa ${ }^{a}$ https://orcid.org/0000-0002-3924-9976 Álvaro Farías Díaz ${ }^{\text {b }}$ https://orcid.org/0000-0002-9942-2793

(a) Médico. Miembro y vicepresidente del Instituto Histórico y Geográfico del Uruguay. Miembro de Honor y ex presidente de la Sociedad Uruguaya de Historia de la Medicina.

(b) Licenciado en Psicología. Universidad Católica del Uruguay "Dámaso A. Larrañaga". Miembro de la Red Iberoamericana de Estudio de las Sectas (RIES).

Indio curandero / ducho en ocultas ciencias, / dame algún talismán / para que ella me quiera. Dame algún talismán / compuesto por tres plumas / y con piedritas negras, / y con piedritas negras como los ojos de ella. Ve que las plumas sean / las de mayor virtud, / de ala de caburé / o ala de urutaú.

FERNÁN SILVA VALDÉS, fragmento de "BRUJERÍA" (1).

\section{RESUMEN}

Continuando con la supervivencia de la medicina primitiva en esta segunda parte se completa la descripción de las principales y más frecuentes prácticas empíricas, finalizando con las terapias alternativas y la práctica curativa desarrollada por sectas. Se agrega un breve capítulo sobre la influencia de la medicina primitiva en el lenguaje médico. Se mantiene el número de orden comenzado en la parte 1.

PALABRAS ClAVE: Historia de la Medicina; Medicina Tradicional; Terapias Complementarias; Terapias Espirituales.

\begin{abstract}
Continuing with the survival of primitive medicine, in this second part we complete the description of the main and most frequent empirical practices, ending with alternative therapies and the healing practice developed by sects. Add a brief chapter on the influence of primitive medicine on medical language. The order number started in part 1 is maintained.
\end{abstract}

KEY WORDS: History of Medicine; Medicine, Traditional; Complementary Therapies; Spiritual Therapies. 


\section{RESUMO}

Continuando com a sobrevivência da medicina primitiva, nesta segunda parte a descrição das principais e mais freqüentes práticas empíricas é completada, terminando com terapias alternativas e com a prática de cura desenvolvida pelas seitas. Um breve capítulo é acrescentado sobre a influência da medicina primitiva na linguagem médica. $\mathrm{O}$ número do pedido iniciado na parte 1 é mantido.

PALAVRAS CHAVE: História da Medicina; Medicina Tradicional; Terapias Complementares; Terapias Espirituais.

\section{9) Hipnoterapia y sugestión}

La sugestión es un proceso psicológico mediante el cual se puede manejar guiar, o dirigir, los comportamientos de una persona. Sin herencia aborigen propia, las supersticiones vinieron de la mano de la colonización europea (trasplante de creencias muy antiguas en el viejo mundo) o introducidas por la esclavatura (trasplante de la muy rica cultura africana). La curación por medio de la sugestión está íntimamente vinculada a la magia, y por tanto en mayor o menor grado influencia todas las formas de tratamiento en la medicina primitiva. La sugestión ha sido el medio empleado por el brujo o chamán. También por alguna forma de tratamiento médico. El médico psicoterapeuta Hugo Silvera Galasso hizo un estudio sobre un rito chamán, una cura en una tribu de los indígenas Cuna, de Panamá vinculándolo a la psicoterapia de la medicina tradicional. En un parto difícil y prolongado fue convocado un chamán por la partera. En la choza yacía la parturienta y allí el chamán desarrolló su ritual (fumigaciones con cacao, invocaciones, cantos). El chamán tiene éxito con las distocias funcionales, pues las anatómicas (fetales o maternas) no responden. Afirma Silvera Galasso que el tratamiento psicológico, como el que emplea el chamán, ha sido eficaz en partos complicados por distocias funcionales, sobre todo en las distocias de contractilidad (hipertonía, hipotonía) donde participa el sistema subcortical límbico. Se obtuvo respuesta favorable con la sedación y aún con la hipnosis, métodos que fueron empleados por la medicina soviética (escuela pavloviana de los reflejos condicionados).
El chamán es un mago, un curandero y un especialista del alma humana, cuyo drama conoce a través de sus experiencias iniciáticas. Ejerce una medicina de naturaleza mágico-religiosa, sobrenatural, donde el concepto de cura por azar o cura por evolución natural del mal le es desconocido. Causalmente explica todo, no tiene dudas. La enfermedad es causada por espíritus o elementos sobrenaturales malos a los que su práctica curativa debe expulsar. O por desequilibrio del alma o fuerzas que regulan la vida, predominando los espíritus maléficos o perdiendo poder los buenos; debe entonces restaurar el equilibrio.

Para la medicina científica, es incomprensible la actividad chamánica, pues se basa en componentes mágico-religiosos que no existen en nuestra forma de curar. ¿No obstante, puede comprobarse algún resultado benéfico que pueda ser explicado por la medicina tradicional? Según Silvera Galasso, que es médico psiquiatra y psicoterapeuta la práctica chamánica es una verdadera psicoterapia.

En el caso del trabajo de parto prolongado, el chamán ejerce su influencia benéfica a través de verdaderas técnicas de psicoterapia donde la confianza en el terapeuta es imprescindible. Su lenguaje actúa por sugestión y persuasión y se complementa y refuerza por la mímica y la pantomima. Provoca así estímulos sensoriales de variada naturaleza que actúan sobre analizadores (receptores) psíquicos y pueden dar lugar a respuestas físicas, tal la restauración del tono uterino normal. En realidad todo es un acto de sugestión con efecto sólo comparable al obtenido en la hipnosis profunda. El parto se produce (2). 
La psicoterapia es un tratamiento científico de naturaleza psicológica que promueve cambios o modificaciones en la conducta, la salud física y psíquica, la integración de la identidad psicológica y el bienestar de las personas. Actúa por sugestión. Ya lo reconocía nuestro poeta nativista Fernán Silva Valdés:

"El curandero no era un pícaro ni un embaucador. El poseía - por herencia paterna y por dedicación - ciertos conocimientos de la ciencia primitiva de curar algunos males del cuerpo y del alma. Por eso se tomaba en serio a sí propio, tanto como lo tomaban sus pacientes, pues algunas curas hacía a base de yerbas medicinales que hoy se siguen usando, y a base de palabras y consejos que curaban por sugestión, como igualmente hoy día siguen curando nuestros médicos especialmente los alienistas. ¿Y si no qué es la psicoterapia?”(3).

\section{0) Medicina "casera"}

Llamamos así a la que se ejercita con los recursos terapéuticos que se tienen "a la mano", que están disponibles en el hogar o sus inmediaciones, fuera de toda preparación según las normas farmacéuticas. Derivan de tradiciones muy antiguas y han sido transmitidas de generación en generación desde la época colonial a partir de las farmacopeas que acompañaban a los viajeros y navíos. He aquí una receta en base a productos de fácil acceso rescatada y gentilmente comunicada por nuestro cofrade del Instituto Histórico y Geográfico del Uruguay, Lic. en Historia Fabián Melogno:

"Para toda clase de heridas

Se compone de esta manera / Media taza Estracto de Saturno / una idem buen Vinagre. Otra / Espiritu de Vino y se rebuelve bien. / Antes de suministrarlo, cosimos / pañitos de tela ó genero de hilo / Se aplica a la parte dolorida / es un remedio eficas. Y para / calmar pronto el dolor de / una quemadura un poco / harina con aceyte y buen vino / se pone en la parte quemada / como un betun y pronto calma / el dolor y si resultan llagas
/ con la dicha compocisión de / agua de heridas y aceyte de / nueses antes se unta la parte / que forma las llagas y despues/// con un trapito de Madras / o si puede ser genero de hilo / se moja, y dicha operasi / se repite de mañana tarde y cuando uno se acuesta a dormir.

Ramón Campos"

La receta aparece manuscrita en una hoja de una ordinaria libreta de almacén con tinta en el recto y verso, sin fechar. Se encuentra en el archivo del general Alfredo R. Campos, en el Dpto. de Estudios Históricos del Estado Mayor del Ejército. En la transcripción he mantenido la ortografía original modificando la puntuación para mayor claridad. El firmante, Ramón Campos (1852-1909) era un español nacido en Santa María de Vincios, cercano a Vigo, Provincia de Pontevedra. Llegó a América en 1870 radicándose en Pergamino, Provincia de Buenos Aires, y ya casado, se vino a Montevideo en 1879. Llegó a poseer discreta fortuna, con casa en el centro y quinta en el Camino de los Molinos y Ariel. Comerciante y asiduo colaborador del periódico "La España" de Francisco Vázquez Cores fue redactor de bases y estatutos de sociedades cooperativas y mutuales. Fue el padre del general Alfredo R. Campos quien conservó el documento (4).

Algunos de los componentes de esta receta que resaltamos en negrita son de muy remota época, tal vez medievales. El Estracto de Saturno (sic) procede de "Saturnus", nombre del metal plomo entre los alquimistas, común en la farmacopea colonial. El Espiritu de Vino es el alcohol etílico; el nombre de "espíritu" fue dado por el médico español Arnoldo de Vilanova (1235-1311), un alquimista, quien defendió con entusiasmo las propiedades del vino. El "espíritu" de la bebida es lo que anima (euforiza) al bebedor, de ahí la calificación de "bebidas espirituosas". El agua de heridas es desconcertante; no he encontrado su significado, salvo que se refiera a la exudación de las áreas quemadas y ampolladas, o al agua de lavado de las mismas. 
Una segunda receta casera la rescatamos de los baúles de nuestros abuelos maternos, repletos de toda clase de objetos y papeles conservados por tradición. Está en una hoja manuscrita sin fecha ni lugar (figura 1):

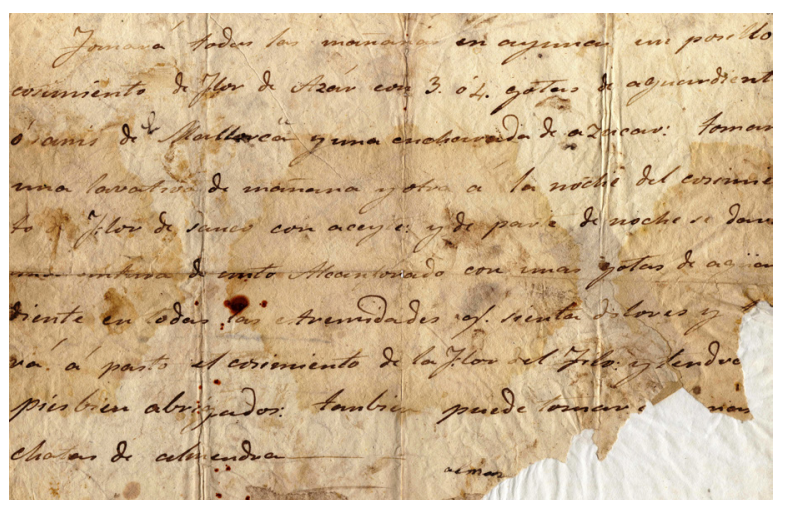

Figura 1. Receta casera de la familia Larrosa-Lamas, localidad de Marmarajá, 7a. sección rural del departamento de Lavalleja.

"Tomará todas las mañanas en ayunas, un pocillo de cocimiento de flor de azahar con 3 o 4 gotas de aguardiente o anís de Mallorca y una cucharada de azúcar:

Tomará una lavativa de mañana y otra a la noche del cocimiento de flor de saúco con aceite, y de parte de noche se dará una untura de unto alcanforado con unas gotas de aguardiente en todas las extremidades que sienta dolores $y$ [tomará] aparte del cocimiento de la flor del tilo y tendrá [los] pies bien abrigados. También puede tomar [roto] [hor]chatas de almendras"

El aguardiente es una bebida con alcohol etílico por destilado de un mosto fermentado y luego diluido en agua. Toma su nombre de "Aqua» y "Ardiente» tal vez por la sensación quemante al ser ingerida. Formó parte de antiguas farmacopeas. La receta afirma que puede ser sustituido por anís de Mallorca, que es una bebida también alcoholizada de alta graduación y que debe su nombre al fruto de la planta con la que suele estar hecho (Pimpinellaanisum) conocida en castellano como "anís" (también del hinojo). Lo de Mallorca tal vez sea por el origen, asequible en esa época (y aún hoy), como bebida de $30 \%$ de graduación alcohó- lica, pues los hay de múltiples lugares. El agua de azahar (el "ma - zhar" de la farmacopea árabe) se prepara destilando la flor del naranjo; se ha utilizado desde hace siglos con fines medicinales, incluso como vehículo de preparados farmacéuticos. La receta incluye una lavativa [enema] aceitosa con un cocimiento de flor de saúco, que es la flor blanca del árbol sudamericano del género sambucus (con hasta 30 especies); al saúco se le atribuyen múltiples acciones medicinales, entre ellas, un efecto laxante, de ahí la enema. El unto es una pasta pegajosa (unto $=$ untuoso) que se extrae de la grasa que rodea el intestino del cerdo, muy apreciada; mezclada con alcanfor (Cinnamomum camphora) por sus propiedades analgésicas, ha sido utilizado en cataplasmas y friegas para calmar dolores musculares leves y lumbociáticas. Finalmente, una infusión de flor del tilo. El tilo es un árbol de gran porte cuyas flores tienen propiedad sedante e inductora del sueño, antitusiva y relajante del músculo liso bronquial. En una época, en la casa de mis abuelos hubo un enorme árbol de tilo cuyas flores eran recogidas en bolsas de arpillera y vendidas a los yuyeros. Tuve información (no confirmada) del uso de las flores de los árboles callejeros de tilo por el Ministerio de Salud Pública, probablemente por su antecesora, la Asistencia Pública Nacional. La orchata (horchata) es una bebida de origen español, sabrosa, refrescante y nutritiva. Básicamente consiste en almendras molidas en agua que proporcionan un líquido blanco como una leche de almendras, al que se agrega azúcar a gusto.

Como se aprecia, es una receta compleja que asocia productos animales y vegetales y revela una antiquísima tradición médica. El paciente recibiría una ínfima dosis de alcohol al despertar en una infusión azucarada, como estimulante (¿sería un convaleciente?). La enema tiene tradición galénica, es una terapéutica para eliminar los "malos humores", inespecífica como lo era la sudoración y la sangría. La aplicación del unto alcanforado nos remite a un paciente dolorido, tal vez un reu- 


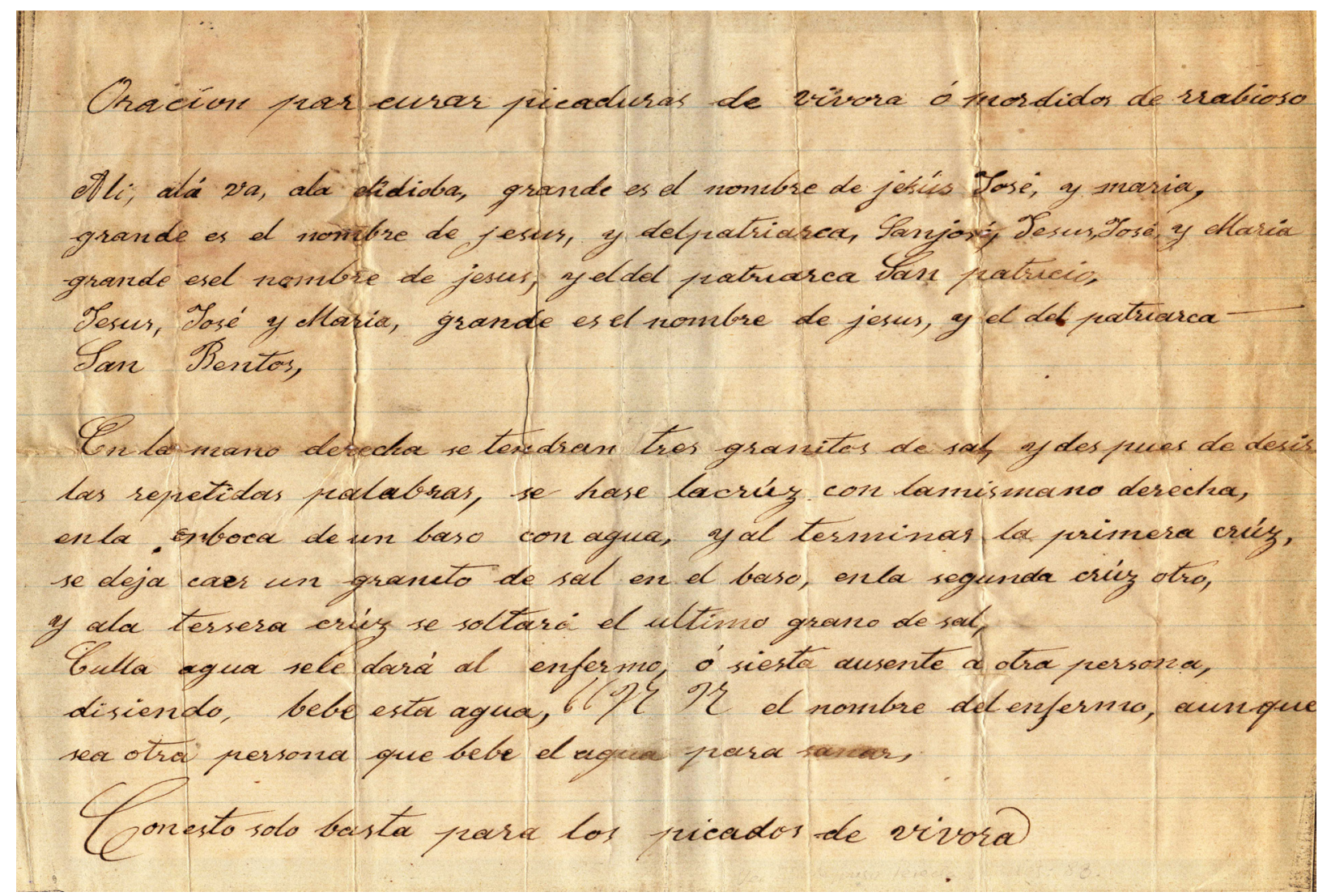

Figura 2. Receta casera de la familia Larrosa-Lamas, localidad de Marmarajá, 7a. sección rural del departamento de Lavalleja.

mático. Y sedado antes de dormir con la infusión de tilo. La horchata agregaría su efecto confortante y nutritivo. El conjunto de indicaciones nos habla de un paciente en cama, tal vez estreñido, dolorido y casi seguramente añoso. Sorprende esa farmacoterapia casera, con siglos de maduración y que combina productos que nos parecen hoy razonables para el pensamiento médico de la época.

Queremos destacar un hecho: ninguna de estas recetas puede provocar daño al paciente excepto cuando recibe metales, según la práctica alquimista. Metaloides o metales, como arsénico y mercurio fueron empleados en medicina hasta casi mediados del siglo XX en el tratamiento, entre otras afecciones, de la sífilis.

Una tercera receta, también del mismo origen que la anterior combina la oración con la ingesta de un vaso de agua "bendecida" y se aplica "para curar picaduras de víbora ó mordida de rrabioso" (figura 2). De gran predicamento popular, fue el manual tera- péutico de Bruno Goyeneche Lasa (Tafalla, Navarra 1849- Rivera, 1936) (5). Emigrante navarro al Uruguay llegó a Paysandú en 1872 como director de una compañía de zarzuela, en plena epidemia de fiebre amarilla. Con conocimientos musicales, maestro de coro y organista, aficionado a la poesía y ocupado como periodista, su afición a la botánica le condujo a redactar un Diccionario de Medicina Rural publicado por entregas en el periódico sanducero El Norte que, una vez llevado al libro, se difundió en Uruguay, Argentina y Paraguay con varias ediciones (6).

\section{1) Homeopatía}

La homeopatía, método de tratamiento creado por el médico sajón Samuel Hahnemann (Meissen, Alemania 1755 - París, 1843) sostiene que la enfermedad sólo cura cuando es destruída por otra enfermedad similar y más intensa. Es el principio "similia-similibuscurantur" que se opone al "con- 
traria-contrariiscurantur" de la medicina alopática. Hahnemann estudió medicina en Leipzig y se graduó en Erlangen en 1779 con su tesis "Consideraciones etiológicas y terapéuticas en las afecciones espasmódicas». Escribió un Ensayo sobre un nuevo principio para averiguar los poderes curativos de las drogas, publicado por primera vez en alemán en el Journal der praktischen Arzneykunde de Hufeland, vol. II, parte III, en 1776. Se considera a ese ensayo como el inicio de la práctica homeopática. Este sistema de tratamiento llegó al Río de la Plata a mediados del siglo XIX de la mano de los médicos y officiers de santé franceses. El general argentino José de San Martín utilizó homeopatía para su asma, gota y úlcera gastroduodenal gracias a un botiquín de 60 medicamentos que le hizo llegar desde Europa su amigo Ángel Correa. El botiquín, que lo acompañó en sus expediciones libertadoras se encuentra en el Museo Histórico Sanmartiniano de la ciudad de Mendoza. En 1834 abrió sus puertas la primera farmacia con venta de productos homeopáticos en Buenos Aires, la "Farmacia De La Estrella", ubicada en una esquina céntrica de la ciudad de entonces. El primer médico que ejerció la homeopatía en territorio argentino fue Guillermo Darrouzain quien en 1845 en Montevideo y 1846 en Buenos Aires abrió consultorio homeopático. Murió en Corrientes ejerciendo ese método terapéutico en 1869, año en que se fundó la Sociedad Hahnemanniana Argentina de breve existencia (7).

En 1873 se editó en Montevideo "Instrucciones para los enfermos que son tratados homeopáticamente en el consultorio filial del Instituto Homeopático de Brasil dirigido por Santiago Estrázulas y Lamas, Profesor de la Escuela y Socio del Instituto Homeopático del Brasil, de Turín y de la Sociedad Hahnemanniana de Buenos Aires" (Montevideo, Imprenta El Mensajero, 1873). Estrázulas (1815-1898) era presbítero y cura párroco de la Iglesia Matriz de Montevideo y ejercía públicamente y sin obstáculos la homeopatía, pues la Junta de Higiene de Montevideo había autorizado en 1850 al sacerdote a ejercer la medicina homeopática. Fue un pionero en la introducción del método homeopático en nuestro país. De conversaciones privadas se recuerda un hecho que es revelador de la simpleza con que se empleó el método homeopático. Un jefe de estación del ferrocarril uruguayo tenía en su oficina un armarito repleto de frasquitos, obviamente remedios homeopáticos. Cuando era consultado por un vecino, preguntaba por el síntoma principal y le decía:

- ¡Espere un momentito!

Y revisaba un librito donde los síntomas eran listados alfabéticamente. Encontrado, iba al armarito y sacaba en frasquito numerado.

- "Me lo toma cada... horas durante... días. Y después me cuenta!

Por ley del 3 de febrero de 1881, se creó la Cátedra de Homeopatía en nuestra Facultad de Medicina contando con su primer profesor, Ramón Valdés García (médico hispano-cubano radicado en Montevideo) y un presupuesto votado por el Senado de la República. Poco duraron cátedra y profesor, cuyo fin, seguramente alentado por los opositores al sistema homeopático, se precipitó por un humillante episodio estudiantil en el anfiteatro donde se desarrollaba la clase. Bien lo ha narrado el Dr. Augusto Turenne en dos artículos que aún hoy, son de lectura obligada pero sobre todo amena sobre el tema (8). En la Gaceta de Medicina y Farmacia editada en Montevideo existe información histórica sobre el trámite de la homeopatía en el Uruguay (9). En 1886 la Cátedra había desaparecido del presupuesto universitario. Si bien Valdés García prosiguió con su tratamiento homeopático, desde aquel incidente en las aulas universitarias quedó marginado de la práctica médica tradicional. Cabe recordar que Valdés García fue el inventor de un tónico llamado "carne líquida" que contó con la aprobación de inocuidad nada menos que por el doctor Santiago Ramón y Cajal en España, según certificado del 2 
de marzo de 1909, que circuló en hoja suelta en Barcelona, y que se comercializó por muchos años. En 1882, pese a la desaparición de la Cátedra se fundó en Montevideo la "Asociación Popular Homeopática" presidida por el abogado Hipólito Gallinal (1861-1921) que llegó a contar con más de 6900 adherentes según su Memoria de la Comisión Directiva (10). Fusionada con la similar "Sociedad Homeopática Uruguaya de Beneficencia y Propaganda" dio lugar a la "Sociedad Hanmemanniana Uruguaya de Beneficencia y Propaganda Homeopática".

Transcribimos (textualmente) de nuestro repositorio de origen familiar ya citado, esta curiosa carta que alude a la homeopatía en el medio rural (figura 3):

"Mi tío Felipe, estoy muy desasonado con muchos dolores en los pulmones, y en la garganta, quiero consultar con $U d$. si estando así podré repetir hoy, Ud ya la ha tomado y debe estar muy impuesto. El otro día le oí decir a Ud que el médico le preguntó a Ud que había sentido y Ud le dijo que muchos dolores, y que él le respondió que ya no se la daba más y podía irse cuando quisiera.

Así estoy yó hoy con muchos dolores y por eso me acordé de lo que le había oído a Ud. desde el martes por la noche que tomé este remedio no he tenido gusto para nada; a si que quiero consultar con Ud a ver que consejo me dá.

Le digo a Ud con verdad que si dios quiere que yo tenga algún alivio me voy a Montevideo o al cielo porque esto ya es mucho penar.

Las dos primeras tomas me desasonaron, pero esta mucho más.

\section{Ud debe saber si la homeopatía viniendo en polvo será mejor que en líquido.}

Entre tanto quiero que Ud me de algún consuelo. La primera que tomé fue mandada tomar con 8 días de intervalo. Esta no son mas que 4. Ud que ya ha tomado mucho debe saber si en este remedio puede haber estas variaciones; todas estas preguntas que yo le hago hágame el favor mandármelas decir por el portador".
Difícil reconocer el mal que afectaba a este enfermo. Parece que lo dominante era el dolor, tal vez en su columna vertebral (por el eufemismo de "los pulmones"). Lo que parece evidente es la terapéutica homeopática, tal vez en gotas, y buscando si la presentación en polvo no le sería más eficaz. Pero de cualquier manera, sin resultado. Lo cierto es que, a pesar del rechazo de la medicina alopática ortodoxa, la homeopatía gozó (y goza) de popularidad.

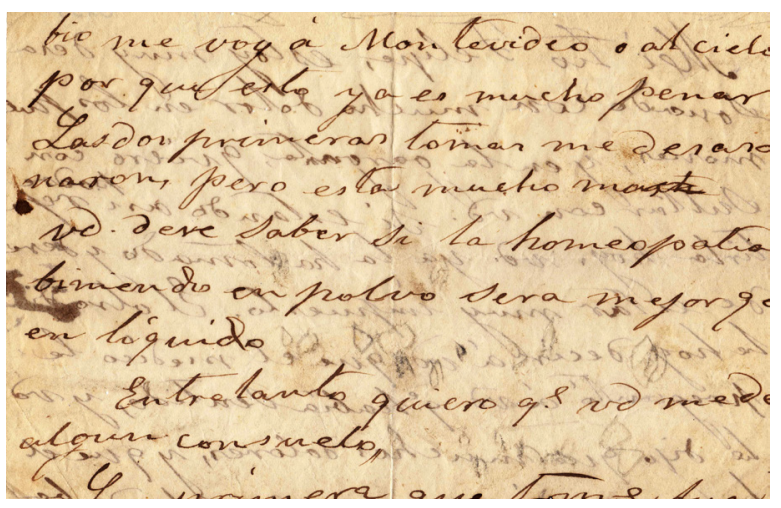

Figura 3. Original manuscrito de homeopatía en el medio rural. Archivo de la familia Larrosa-Lamas.

“La Homeopatía debe ser ejercida por médicos, veterinarios u odontólogos, como cualquier especialidad terapéutica. En nuestro país existen dos Asociaciones Médicas que dictan cursos de formación para médicos [Asociación de Medicina Homeopática Uruguaya y Escuela de Medicina Homeopática Hahnemanniana del Uruguay]. Existen más de cien médicos que han cursado la especialidad. Sin embargo, al no ser aún reconocida como acto médico por el Ministerio de Salud Pública, ni como posgrado por la Escuela de Graduados de la Facultad de Medicina, es comúnmente practicada por idóneos, farmacéuticos o quien quiera hacerlo, lo cual genera una situación de irregularidad y desprestigio. Muchos médicos en nuestro medio confunden la Homeopatía con prácticas mágicas o metafísicas" (11).

En 2016 Uruguay aprobó por decreto un Marco regulatorio de los Medicamentos Homeopáticos, decreto 404/016 del 19 de diciembre de 2016. 


\section{2) Acupuntura}

Es una técnica de la medicina no occidental, forma parte de una práctica curativa de miles de años, asiste a millones de seres en un vasto continente y progresivamente ha sido aceptada fuera de Oriente. En esencia trata de restablecer el equilibrio dentro del cuerpo de dos fuerzas antagónicas en el mundo que dominan la filosofía china: la positiva (yang) y la negativa (yin). Estas fuerzas circulan en el cuerpo bajo forma de energía a través de doce líneas llamadas "meridianos" (bilaterales y mediales). Se considera a la enfermedad como consecuencia del predominio de una u otra fuerza. Restablecer el equilibrio es conseguir la cura. El acupunturista chino hace el diagnóstico por la observación del enfermo (rostro, lengua, cabello, ojos, líneas de la mano), su interrogatorio (que no es solamente de hechos médicos), palpación del abdomen y prolongadamente, del pulso arterial, que vendría a ser la exploración de mayor rendimiento. Del conjunto extrae la causa de la enfermedad y su pronóstico. Parecería que la técnica de examen podría diagnosticar un embarazo, el sexo de un bebé por nacer y aún la fecha probable de muerte de una persona en días. Pero estos poderes parecen estar reservados al Oriente pues los acupunturistas occidentales están privados de la sensibilidad de sus colegas chinos, al menos en la lectura del pulso. Respecto al tratamiento, se utilizan agujas que se introducen en complejas combinaciones de puntos seleccionados sobre los meridianos (365 puntos energéticos), según la energía que se quiere estimular en la parte del cuerpo que corresponde a aquellos. La técnica de su introducción es de una extraordinaria minuciosidad, pues el resultado podrá variar con agujas de oro o plata, inmóviles o vibrátiles, más o menos profundas, en inspiración o espiración, dirección, temperatura, permanencia y número de sesiones. A lo que habría que agregar el estado moral del paciente, hora, día, estación anual, región y clima. El acupunturista debe ser por tanto un super especialista. En el siglo VI se introdujo en los países vecinos a China, donde se aceptó con facilidad, y a comienzos del siglo XVI llegó a Europa, introducida por los misioneros que volvían de China. En el siglo XVIII adquirió un impulso extraordinario. En la primera mitad del siglo XIX clínicos eminentes del país dominante en la medicina occidental -Francia- como Pierre Bretonneau, René Laënnec y Armand Trousseau se interesaron y numerosos hospitales de París la introdujeron. De tal forma que la acupuntura desde el fin del siglo XIX conservó en Francia prestigio hasta nuestros días y fieles practicantes. Pero a la misma se le puede aplicar el concepto de medicina primitiva y empírica pues el misterio rodea a todo el procedimiento, desde el diagnóstico al tratamiento. ¿No habría un efecto psicológico afín a la sugestión que permitiría al enfermo sentirse mejor?.

Se considera que muchos elementos de la medicina tradicional, aún sin interpretación racional, son beneficiosos y la Organización Mundial de la Salud (OMS) animó a los Estados Miembros a identificar medicamentos y prácticas inocuas y eficaces para su utilización en los servicios de salud públicos y privados. La OMS en 1991 (44 ${ }^{\text {a }}$ Asamblea Mundial de la Salud) instó a los Estados Miembros a introducir medidas para su reglamentación y control (Resolución WHA44.34) (12). En Uruguay, la acupuntura fue introducida a principios de la década de los años 70s por algunos médicos pioneros. En 1980 comenzó en la policlínica del Hospital Maciel; en 1983 en el Hospital Militar; en 1990 en el Hospital de Clínicas y en 1999 en el Hospital Policial así como en varias instituciones de salud privadas. En 2001 se habilitó la actividad como acto médico por decreto del Poder Ejecutivo (Decreto 32/001 del 31/01/2001). Y se extendió la habilitación a los profesionales odontólogos por Decreto 131/002 del 16/04/2002. Constituye una de las cuatro terapias alternativas autorizadas (acupuntura, homeopatía, reflexología, reiki). Por tanto sólo puede ser realizada por profesionales médicos u odontólogos, debido a que exige un diagnóstico previo de la afección que se 
necesita tratar, al igual que una correcta evaluación de los resultados. Pero continúa sin ser integrada a la enseñanza médica oficial.

\section{LAS TERAPIAS ALTERNATIVAS Y EL TEMA DE LAS SECTAS}

\section{3) Terapias alternativas ¿o manipulación psicológica?}

Hombres y mujeres de nuestra cultura de fines de siglo XX y principios del siglo XXI, están atravesados por un particular "sentimiento de malestar" (Freud, 1930). Naufragio, nihilismo, desesperanza, soledad... son algunas de las notas que parecen caracterizar este particular modo de ser que ha sido llamado "postmodernidad". En la "modernidad" las personas estaban, en mayor o en menor medida, todas sujetas al relato político, científico, filosófico y también al discurso religioso. La "postmodernidad" ha significado la caída de estos relatos que daban sentido a la existencia. El sujeto postmoderno fragmentado, disociado, alienado, busca afanosamente un discurso que legitime su existencia (13).

El sentimiento de naufragio es el que predomina en nuestros días; algunas estadísticas sostienen que cerca de un $20 \%$ de la población sufre depresión. La farmacoterapia combinada ha sido la respuesta cientificista. El psicoanálisis, la "cura a través de la palabra", paradigma revolucionario desde hace ya 100 años, habría perdido algo de su fuerza revolucionaria.

Frente al cientificismo erigido religión y frente a las ciencias cognitivas que valorizan al hombre, han florecido como consecuencia de aquel naufragio, toda una serie de prácticas surgidas, ya de la prehistoria del freudismo, ya de una concepción "ocultista" del cuerpo y el espíritu. Se asiste en las sociedades occidentales a un increíble auge de ensalmadores, hechiceros, videntes y magnetizadores; sofrología, naturopatía, iridología, auriculoterapia, energética transpersonal, prácticas mediúmnicas y de sugestión (14).
En la década de los '60, principalmente en California, apareció un movimiento de contracultura, un conglomerado de ideas que fue bautizado (o rebautizado) como New Age (Nueva Era) intentando propagar una nueva conciencia. Miles de jóvenes dijeron no al sistema y se enfrentaron a la autoridad. El consumo de drogas alucinógenas, como el ácido lisérgico y las alteraciones de conciencia así provocadas, les permitió alcanzar aquellos "nuevos niveles de conciencia". Transcurrido ya medio siglo, no se trata de "cambiar el sistema" sino ahora "cambiarse a sí mismo. En esa búsqueda del yo las religiones orientales están más cerca que las occidentales pues valoran más la experiencia interior que los logros externos; persiguen la armonía con la naturaleza más que su explotación. Se ha pasado del "prohibido prohibir" de mayo de 1968 a un "sí, maestro". Surge la fascinación por las ofertas religiosas que se codean con la ciencia, que irrumpen por caminos que parecían ya poco transitados o reservados a los marginados de la religión ortodoxa. No sorprenden ciertos programas de televisión, de radio, avisos en diarios y revistas en donde aparecen "ofertas religiosas" mezcladas con "ciencia" como la radiestesia, control mental, reiki, budismo, meditación trascendental, viajes astrales, Jesús cósmico, Iglesias Neopentecostales, grupos gnósticos. Los intentos de explicación de este fenómeno son varios (15).

Uno de ellos es precisamente el de una "Nueva Era": nos hallaríamos ante el inicio de una nueva época (la de Acuario) que supone una sensibilidad diferente de la que ha predominado hasta hoy (la de Piscis), más belicosa, delimitativa, institucionalizada y racionalista. Esta nueva conciencia hunde sus raíces en el intento de encontrar puntos de contacto entre ciencia y religión, entre razón y magia, entre Oriente y Occidente. Una de las principales divulgadoras del pensamiento New Age, Marilyn Ferguson en el que seguramente es su libro más famoso, "La conspiración de Acuario" (16), habla de las principales 
psico-técnicas que hay que emplear para alcanzar la transformación de la conciencia, y entre ellas incluye la hipnosis, la meditación, grupos de ayuda, técnicas de biofeedback, técnicas chamánicas, seminarios para el desarrollo del potencial humano, teosofía, terapias corporales, bioenergética, disciplinas orientales. Según ella, para que se de esta transformación habría que recorrer 4 etapas: a) un despertar por un estímulo adecuado (una película, un libro, una alucinación por una droga, la recitación de un mantra); b) gracias a técnicas como el zen, el yoga, la bioenergética, llegará el momento de explorar el cuerpo y la mente de donde resultaría la "unificación de las energías"; c) esa integración energética suele traer consigo el "viaje astral" en donde se percibe la "memoria del Universo" y se llega a tener un conocimiento superior que permite realizar lo que se desee con solo pensarlo ("yo soy" Dios); d) el estado alcanzado irradia hacia todo lo que le rodea, hasta conseguir la transformación que él ha experimentado. Hay que aclarar qué es lo que en la New Age se entiende por "Dios". Dios sería la "energía" que en un momento determinado descendió sobre Jesucristo, Buda, Mahoma. La crucifixión, resurrección y ascensión de Jesucristo sería la liberación de aquella energía y su difusión a modo de gas vivificador del cielo nuevo y la tierra nueva, que se manifestará en todo su esplendor cuando ocurra el advenimiento de la "Nueva Era" o "Era de Acuario".

Cualquiera puede llegar a ser "Cristo", para ello hay que recurrir a las técnicas New Age y sobre todo provocar estados alterados de conciencia (trances místicos, fenómenos de channeling o canalismo). A partir de la práctica del "channeling" se puede invocar la asistencia de los llamados "Maestros Ascendidos", verdaderos guías de la humanidad que dictarían en la conciencia a las personas el qué hacer, sentir, pensar, de manera que cada uno invocando a su "Maestro Ascendido" de turno, puede llegar a justificar cualquier decisión por irracional que parezca.
Estos "maestros ascendidos", son hermanados y yuxtapuestos unos a otros en una perpleja y solidaria enumeración: Henoc, Elías, Moisés, Paracelso, El Morya, Noé, Mahachohan, Pitágoras, Confucio, Jesús de Nazareth, Hermes Trismégisto, Elohim, Buda, Nichiren, Mahoma, Krishna, Melquisedec, Maitreya, El Rey Arturo, Minerva, Nabucodonosor, Serapis Bei, Lady Rowena, San Juan Bautista, Eliphas Lévi, Sanat Kumara, El Arcángel Miguel, M. Eckhart, Nanak, Francis Bacon, La Virgen de Fátima, El Conde de Saint Germain. Todos ellos serían manifestaciones del único 'Cristo cósmico' (17).

El mayor problema con todo esto es la utilización perversa de estas creencias y técnicas. Muchas de las ofertas terapéuticas que aparecen en los anuncios que podemos ver en las paradas de ómnibus, en la radio, en revistas y en programas de televisión van desde la terapia reikista, angeológica, terapia floral, curación con cristales, yoga, chamanismo, regresiones a vidas pasadas, el Instituto Nefrú del Maestro Rolland, la Metafísica New Age, la BioNeuroEmoción de Enric Corbera. La lista es interminable. En una mayoría de estos casos no hay al frente de las ofertas terapéuticas un profesional idóneo, un psicólogo o un psicoterapeuta formado para el ejercicio de tal función. Cuando lo hay se dan fenómenos de intrusismo profesional y abuso terapéutico. En su investigación en la Universidad Autónoma de Madrid, Rodríguez y Almendros afirman que el $97 \%$ de las personas que habían estado en pseudoterapias afirmaba haber sufrido abuso verbal por parte del "terapeuta"; el $86 \%$ se sintió dañado por la experiencia; el $78 \%$ recibió malos tratos; el $50 \%$ sufrió depresión; el $25 \%$ tuvo relaciones sexuales con el "terapeuta" (18).

La clínica con pacientes que han vivido este tipo de experiencias y con sus familiares nos muestra que estos "terapeutas" terminan siendo verdaderos manipuladores ya que con su forma de actuar denotan un desconocimiento de la ética profesional trasgrediendo los límites de la misma, hacen 
un mal uso de las técnicas psicoterapéuticas y llevan a cabo un manejo de la relación terapéutica en su beneficio personal. El funcionamiento más común de este tipo de terapeutas como lo afirma Perlado es de tipo dominante, con fuertes tendencias narcisistas, aspectos de grandiosidad y paranoidismo, mostrándose como personas muy hábiles verbalmente. En este tipo de "terapias", los límites terapéuticos se diluyen y los pacientes terminan por transformarse en verdaderos creyentes o adeptos, se establece una co-dependencia donde el "terapeuta" y sus pacientes transforman la experiencia terapéutica en un sistema cerrado. Llegan a ser amigos de sus "terapeutas", empleados, colegas, aprendices; y a convertirse en "hermanos" agrupados con el fin de admirarle y darle apoyo $(19,20)$.

\section{4) Las sectas}

Es difícil definir qué es una secta. Margaret Singer emplea la expresión 'relación sectaria' en la que una persona induce intencionalmente a otras a volverse total o casi dependientes de ella respecto de casi todas las decisiones importantes de la vida e inculca en esos seguidores la creencia de que ella posee algún talento, don o conocimiento especial. $Y$ "secta" sería la resultante de esa relación al conformarse un grupo con un líder poderoso que impone un programa coordinado de manipulación psicológica a sus integrantes (lo que más comúnmente se denomina "lavado de cerebro") (21).

¿Cómo se llega a esta situación? Desde un enfoque psicoanalítico se produce una perversión del vínculo transferencial encaminada a alimentar el yo narcisista del líder $(19,20)$.

En la práctica psicoanalítica el paciente es conducido por un camino desconocido de antemano que va orientado, entre otras cosas, a disolver la dependencia derivada de la transferencia e incrementar su autonomía. En cambio, en el discurso dogmático y sectario, esa transferencia se asume por el adepto como cierta y no como una fantasía.
Es una verdadera manipulación del vínculo transferencial. En los testimonios de personas afectadas por este fenómeno, podemos ver como a poco de iniciar el "tratamiento" se comienza a llevar a cabo el proceso de manipulación psicológica (22). Todo comienza con una seducción sigilosa, un "proselitismo engañoso" (23), pero a la persona que consulta nunca se le informa el verdadero trasfondo sectario que este tipo de prácticas terapéuticas tienen. A poco de comenzar el tratamiento, y gracias a procesos fundamentalmente inconscientes, se le irán transfiriendo todo un nuevo sistema de creencias que, de haberlo sabido antes, tal vez la persona no los hubiese aceptado. Poco a poco se incrementará la asimetría, el "terapeuta" se autoimpondrá títulos como "Maestro", "Gurú", "Apóstol”. A partir de este "estatus de superioridad" junto con una actitud "paternalista benevolente" logrará que el paciente haga "confesiones íntimas", iniciándose así la espiral de la captación manipulatoria. Este proceso de manipulación psicológica termina siendo una violenta intrusión en la estructura psíquica del paciente, implantándole objetos internos nuevos, llegándose incluso a negar la parentalidad y el discurso social. Es un proceso de violencia psicológica que genera fuertes estados regresivos y una gran dependencia, que transforma al sujeto en instrumento del "terapeuta". Lo que explica en parte el porqué de la gran dificultad de abandonar este tipo de relaciones. Termina por darse una lógica dual, maniquea, escindida, en donde todo lo bueno está dentro de la relación con el "terapeuta" y todo lo malo fuera. El terapeuta explota al máximo esa dependencia para su beneficio personal.

Las personas tienden a consultar a estos "terapeutas" generalmente en situaciones de crisis. No es tan importante el contenido de la crisis (económica, afectiva, existencial) sino el hundimiento de las convicciones básicas del sujeto y el incremento de vulnerabilidad consecuente. En una instancia de crisis, la confianza en objetos internos buenos y continentes se pierde y es 
entonces cuando el "terapeuta" se introduce para llevarlo a la condición de adepto. El "bombardeo de amor", el otorgamiento de "padres espirituales", el "sobredimensionamiento de los conflictos", sobre todo los familiares (pero también los del trabajo, estudio y sociales en general), será la manera de comenzar un ataque a los objetos parentales (de hecho, este tipo de "terapeutas" se presentan generalmente como padres o madres perfectos). Para luego ser sustituidos por verdaderos "objetos internos implantados mediante un proceso de infiltración masiva en la mente del sujeto que terminará por despojarlo de su mundo simbólico llevándolo a un estado de no - pensamiento" (21).

Seducido el sujeto y atacado su equilibrio narcisista se ponen en marcha prácticas destinadas a desmantelar el yo ("atrofiamiento de identidad, memoria y pautas de vida"), a desmantelar el aparato mental. Las consecuencias del accionar de este tipo de "terapeutas" perversos son familias fracturadas, personas explotadas al extremo, graves trastornos psiquiátricos, suicidios.

El 19 de noviembre de 1978, cadáveres de 913 hombres, mujeres y niños fueron encontrados por tropas guyanesas en Jonestown (Guyana, Sudamérica) (figura 4). Se trataba de un suicidio masivo, el mayor de la historia moderna, por ingestión de jugos de fruta adicionados con cianuro de sodio. Los muertos eran miembros de una secta, el "Templo del Pueblo" dirigido por el reverendo norteamericano Jim Jones quien había creado el asentamiento en 1975 en Guyana, al cual se desplazaron en masa sus fieles desde San Francisco en 1977. El asentamiento se encontraba en la selva profunda, sin carretera de comunicación con la capital de Guyana, con una pequeña pista de aterrizaje y aeropuerto a varias millas. Algunos miembros de la secta abandonaron el asentamiento y se contactaron con la embajada de su país en Georgetown, lo que motivó la intervención del Departamento de Estado de Norteamérica. Las quejas y pedidos de ayuda incluían maltratos físicos y sexuales, separación de los hijos y sus padres, esposas obliga- das a relaciones sexuales con otros hombres. La crisis se desató por la intervención del representante oficial de California que trató de investigar in situ la realidad de la vida en la secta para informar a los Departamentos de Estado y Justicia. Desde ese momento se estableció un conflicto que culminó en choques armados y la decisión de morir de todos los miembros de la secta, arrastrando en su decisión a sus hijos (24).

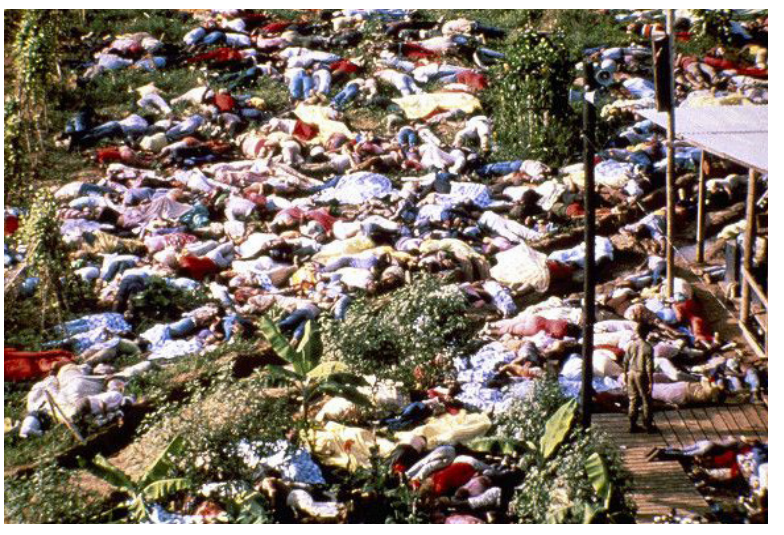

Figura 4. Jonestown Guyana, Sudamérica, 1978. Extraído de BBC News.

\section{MEDICINA PRIMITIVA Y LENGUAJE MÉDICO}

\section{5) Lenguaje médico técnico}

La mayor parte de los vocablos de uso cotidiano entre los médicos tienen raíces griegas o latinas. Establecen analogías entre objetos y cosas del mundo circundante con la anatomía humana y las enfermedades. El lobo es un animal feroz cuya mordida desgarra y mutila. En lengua griega este animal es lupus. Este nombre -a través de las lesiones observadas- terminó vinculándose con una enfermedad cutánea. Casos anecdóticos de enfermedad llamada lupus aparecen en documentos tan antiguos como el siglo $\mathrm{X}$, tal vez formas ulceradas de enfermedades sistémicas o exóticas. La ulceración recordaba las lesiones ocasionadas por los lobos (lupus). Formas de tuberculosis cutánea fueron denominadas /upus en el 1800 y subsiste aún hoy en el lupus vulgaris. Se le atribuye al médico francés Pierre Louis Cazenave (1795-1877) 
la creación del vocablo lupus eritematoso que apareció por vez primera en el artículo Des principales formes du lupus et de son traitement en la Gazette des hôpitaux (París, vol. 23, 1850, pág. 354). Un año después se volvió a utilizar en un trabajo de los Annales des maladies de la peau et de la syphilis. Cazenave ilustró con grabados el lupus en su obra dermatológica (en colaboración con Henri Édouard Schedel) Abrégé pratique des maladies de la peau ( $1^{\text {a }}$ edición, 1828), texto muy influyente en la primera mitad del siglo XIX (figura 5). El dermatólogo húngaro Moritz Kaposi (1837-1902) fue el primero en utilizar la denominación de lupus discoide en 1860, para describir el lupus cutáneo como hoy lo conocemos.

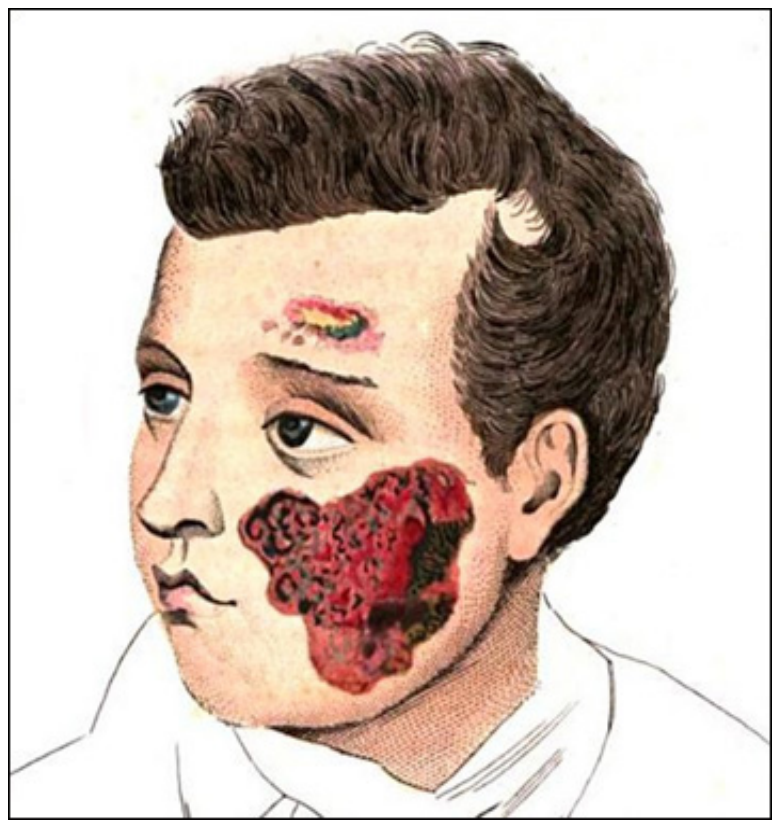

Figura 5. Lupus. Imagen procedente de la edición de 1847 del Abrégé pratique des maladies de la peau.

El hongo es conocido como fungus en latín o mykon en griego. Derivan de allí la micosis fungoide, enfermedad que "levanta la piel rompiéndola de dentro-fuera, como crece el hongo en la tierra". Mykon y micosis están naturalmente vinculados. El afrechillo de trigo o salvado es en latín furfuro pityron en griego. De allí derivó pitiriasis, vocablo que se emplea para diversas enfermedades de la piel caracterizadas por descamación en pequeñísimas escamas como el salvado (descamación furfurácea).
¿Diabetes mellitus? Obviamente una enfermedad endócrina. ¿Pero, porque mellitus? Mellitus es "miel" en latín, cuyo sabor es dulce. Los médicos antiguos probaban la orina de sus enfermos: si era dulce, azucarada, tenía una orina mellitus. En algunas formas de diabetes, la glucosuria (orina azucarada o mellitus) es un signo clásico de laboratorio.

\section{6) Lenguaje médico popular}

En el habla popular se observan sentencias, refranes (paremias) y adjetivos de raíz médica.

- “Pegajoso como la sarna”. Cargoso. La sarna es una dermopatía muy contagiosa por contacto directo. Por "sarna" puede ser identificada la verdadera escabiosis (ácaro Sarcoptesscabieio "arador de la sarna") u otra enfermedad cutánea eczematosa, pruriginosa y rebelde o difícil de curar ("pegajosa").

- “Estiró la pata”. Murió. La observación popular descubrió que la muerte (a veces) se antecede de espasmos musculares o mioclonias o convulsiones tónicas de los miembros.

- “Le dio el mal". Lipotimia. Desmayo. Por analogía a las crisis del "gran mal epiléptico", enfermedad considerada en la antigüedad como "mal divino".

- "Se le revolvió la bilis". Enojo. Ira. Malhumor. El "temperamento bilioso" era en el concepto hipocrático de los cuatro "humores", sinónimo de malhumorado.

- “Apestado". Enfermo. Vinculado con las epidemias de peste en la antigüedad.

- “Manflora”. Afeminado. Débil. De raíz griega. Hermafrodito o Hermafrodita era en la mitología griega el hijo de Afrodita y de Hermes, en honor de los cuales recibió el nombre una mezcla de los de sus padres. Ese atributo se extendió a los que tenían vestigios de ambos sexos. Claro que hermafrodita no se usa en el lenguaje popular, pero sí manflorita que por eliminación del diminutivo quedó en manflora. Juan Carlos Guarnieri lo incluyó en su Nuevo vocabulario campesino rioplatense (25) junto con otros ejemplos citados más arriba. 
- “Empachado”. Indigestado. El empacho es una "indigestión de la comida" y el término indigestión es un "trastorno que por esta causa padece el organismo", cuando existe un alimento o alguna substancia "que no se digiere o se digiere con dificultad; definición del Diccionario de la Real Academia Española de la Lengua, Madrid, edición de 1992. Para los médicos es una "dispepsia", vocablo de origen griego (dys, mal y pepten, cocer). A su vez, "empacho" deriva del francés antiguo, empêcher (impedir, obstaculizar). Lo que parece estar más de acuerdo con el significado popular de "obstruido, atascado" según el pediatra uruguayo rochense Juan Gabito Farías:

"Empacho, expresión popular del <embarras gastrique> cuyo significado es detenimiento $o$ atascamiento gástrico. Venía por consiguiente la severa dieta, el purgante para acelerar el tránsito y el lavaje para la limpieza del intestino. ¡Qué gran satisfacción para los familiares y para el médico cuando este lavaje era generosamente evacuante!. Como es lógico, con la dieta y el reposo en cama se producía una "constipación opiniâtre" [obstinada] la que a su vez requería nuevos laxantes y enemas" (26).

Por supuesto, el "empachado" era habitualmente sometido (y lo es) a las artes del curandero o de la vecina práctica en estas lides más que del galeno, a quien se recurre cuando el mal es grave, incluso quirúrgico. Recomendamos al lector interesado el trabajo pediátrico uruguayo de lleana Algazy-Bailey Creencias populares en pediatría. Investigación a nivel hospitalario (27) y la obra específica sobre el empacho en el Uruguay con abundante bibliografía del médico mexicano de la Universidad Nacional Autónoma de México, especializado en medicina familiar y antropología social Roberto Campos Navarro (28).

DECLARACIÓN DE CONFLICTOS DE INTERESES: Los autores no reportan ningún conflicto de interés. El estudio se realizó con recursos propios de los autores y/o la institución a la que representan.

\section{REFERENCIAS}

(1) Silva Valdés F. Poemas Nativos. 6a.ed. Montevideo: Talleres Gráficos Monteverdey Cía., 1940.

(2) Silvera Galasso H. Enfoque racional de un rito chamán. Primeras Jornadas de. Psiquiatría e Higiene Mental. Tomo I.

Montevideo, diciembre de 1967, p. 194-90.

(3) Silva Valdés F. El curandero. Cuentos del Uruguay. Evocación de mitos, tradiciones y costumbres. 1a.ed. Buenos Aires : Espasa-Calpe Argentina, 1945 , p. 39.

(4) Campos A. Recuerdos desvaídos.

Montevideo: Inst. Hist. Militar "Gral.José Artigas", 1999 , p. 9.

(5) Schulkin A. Historia de Paysandú. Diccionario Biográfico. Tomo 2. Montevideo, 1968, p. 160.

(6) Goyeneche B. Diccionario de Medicina Rural o sea Propiedades Medicinales de las Plantas del País. 1a. ed. Paysandú : Vázquez, Gómez y Cía. Editores, sf, [¿1907?], 86 p. La 2a.ed., corregida y aumentada, 1932, $140 \mathrm{p}$.

(7) Cataldi G. Historia de la homeopatía Argentina. El Homeopático. Disponible en: https://elviajeinterior.wordpress.com/2010/11/04/historia-de-la-homeopatia-en-argentina/ [Consulta 14/11/2019].

(8) Turenne A. Vida, pasión y muerte de la Cátedra de Homeopatía de la Facultad de Medicina. Arch Urug Med Cir Esp 1946; 28(5-6).

(9) Inauguración de la Cátedra Oficial de Homeopatía en la Facultad de Medicina Montevideana [sic] después del último Congreso Internacional celebrado en Londres.

Gac Med Farm 1882; 1(8):285-88.

(10) Korovsky P. La homeopatía en el Uruguay. Un poco de historia. Disponible en: http://homeopatia13drpablokorovsky.blogspot.com/p/la-homeopatiaen-uruguay-un-poco-de.html [Consulta 15/10/2019]. 
(11) Puppo T. Estado actual de la homeopatía en el Uruguay. Informe. Disponible en: https://www. smu.org.uy/publicaciones/noticias/noticias91/homeopatas.htm [Consulta 20/10/2019].

(12) Organización Mundial de la Salud. Directrices sobre capacitación básica y seguridad en la acupuntura. Ginebra : OPS, 2002.

Disponible en: https://apps.who.int/iris/bitstream/ handle/10665/67750/WHO_EDM_TRM_99.1_ spa. pdf;jsessionid=D4DEDBEB99CB87446EFD5 12E6F75CD6D?sequence=1 [Consulta 20/10/2019].

(13) Farías Díaz A. Terapias alternativas o manipulación psicológica. Las pseudoterapias New Age. Trabajo presentado a las II Jornadas "Más allá del consultorio", Asociación Uruguaya de Psicoterapia Psicoanalítica, Montevideo, 1 y 2 de agosto de 2008. XIX Jornadas Uruguayas de Psicología "Los miedos: realidad de nuestro tiempo", Sociedad de Psicología del Uruguay, Montevideo 29, 30 y 31 de agosto de 2008. VI Congreso y XVI Jornadas APU, "Desafíos al Psicoanálisis Contemporáneo", Montevideo 19, 20 y 21 de agosto de 2010.

(14) Roudinesco E. ¿Por qué el psicoanálisis?. Buenos Aires : Paidós, 2002. 136 p.

(15) Farías Díaz A. Postmodernidad, el retorno de Dios. 2004. Disponible en: https://www.monografias.com/trabajos17/retorno-dios/retorno-dios.shtml [Consulta 20/10/2019].

(16) Ferguson M. La conspiración de Acuario. Barcelona : Kairós, 1985. 24 p.

(17) Pastorino M. New Age: la punta del iceberg. Quincenario "Entre Todos". Montevideo, 2004. Disponible en: https://es.catholic.net/op/articulos/ 2344/cat/18/new-age-la-punta-de-un-iceberg.html [Consulta 20/10/2019].
(18) Rodriguez C, Almendros C. Ladrones de libertad: pseudoterapias "religiosas" New Age.

Madrid : Universidad Autónoma de Madrid Ediciones, 2005.

(19) Perlado M. Intrusismo profesional y abuso terapéutico en grupos de manipulación en salud mental. Revista del Colegio Oficial de Psicólogos de Cataluña, 2002; 149:2-7.

(20) Perlado M. A propósito de un tipo especial de perversión narcisista.

Revista de Psicoterapia Psicoanalítica 2002; 5:73-87.

(21) Singer M. Las sectas entre nosotros. 3a.ed. Barcelona : Ed. Gedisa, 2003.

(22) Farías Díaz Á. Ladrones de libertad, un abordaje psicoanalítico al fenómeno de la manipulación psicológica sectaria. Memoria de Grado en la Universidad Católica del Uruguay, 2006 (Inédito).

(23) Baamonde JM. La Manipulación psicológica de las sectas. Madrid : Editorial San Pablo, 2003.

(24) The Guyana Tragedy. An international forensic problem. Forensic Sci Int 1979;13(2):167-72.

(25) Guarnieri JC. Nuevo vocabulario campesino rioplatense. Montevideo : Florensa y Lafón, 1957.

(26) Gabito Farías J. Dogmas, mitos y modas en 30 años de pediatría. Montevideo: Mimeográfica Índice, 1977. Folleto mimeografiado sin paginar (archivo personal).

(27) Algazy-Bailey I. Creencias populares en pediatría. Investigación a nivel hospitalario.

Rev Med Urug 1990; 6:23-33.

(28) Campos Navarro R.

El empacho en Uruguay, 1710-2018.

Ciudad de México : Editorial Graffitti, 2018, 189 p. 